\title{
Мультикультурализм и проблемы самоопределения этнокультурных меньшинств
}

Ирада Нуриева Тофик Гызы, Азербайджанский Государственный Университет Нефти и Промышленности

В статье на тему «Мультикультурализм и проблемы самоопределения этнокультурных меньшинств» дано разъяснение концепции мультикультурализма, проявления его в политике государства и решение проблемы самоопределения национальных меньшинств и этнических групп в международной практике, показаны и ведены схожие и отличительные черты с Нагорным Карабахом, который является территорией Азербайджанской Республики.

Самоопределения можно добиться и без создания новых суверенных государств. В международной практике имеет место и другой уровень самоопределения: национально-культурная автономия, которая способствует сохранению представителями разных этнических сообществ, в частности малочисленными народами, национальными и иными меньшинствами самобытного образа жизни, своих языков, культур, традиций и т.д. в рамках верховенства территориальной целостности и суверенных прав государств, на территориях которых они проживают.

Любой народ, любая нация способны выжить и развиваться только в случае сохранения специфичности своей культуры, культурной идентичности. Азербайджан твердо придерживается принципов независимого, правового и демократического общества. Азербайджанская Республика всегда заявляла, что защита прав и свобод граждан рассматривается как определяющий фактор существования демократического общества.

Ключевые слова: мультикультурализм; государственная политика; право на самоопределение; национально-культурная автономия

\section{Multiculturalism and the problems of self-determination of ethnocultural minorities}

\section{Irada Nuriyeva Tofiq, Azerbaijan State University of Oil and Industry}

The article on «Multiculturalism and the problems of self-determination of ethnocultural minorities» covers an explanation of the multiculturalism concept, its manifestation in state policy and the solution of the problem of selfdetermination of national minorities and ethnic groups in international practice. The similar and distinctive features are derived and shown with Nagorno-Karabakh, which is the territory of the Republic of Azerbaijan.

Self-determination can be achieved without the formation of the new sovereign states. There is also another level of self-determination in the international practice: national and cultural autonomy promoting the preservation by the representatives of different ethnic communities, in particular, by small ethnic groups, national and other minorities, of their own way of life, their languages, cultures, traditions, etc. within the supremacy of territorial integrity and the sovereign rights of the states on the territories they live.

Any nation, any population can survive and develop in case of preservation of specify of their culture, cultural identity. Azerbaijan firmly adheres to the principles of an independent, legal and democratic society. The Republic of Azerbaijan has always stated that the protection of the rights and freedom of citizens is regarded as a determining factor in the existence of a democratic society.

Keywords: multiculturalism; state policy; right to self-determination; national and cultural autonomy

\section{Мультикультуралізм і проблеми самовизначення етнокультурних меншин}

\section{Ірада Нурієва Тофік Гизи, Азербайджанський державний університет Нафти і Промисловості}

У статті на тему «Мультикультуралізм і проблеми самовизначення етнокультурних меншин» дано роз'яснення концепції мультикультуралізму, прояву його в політиці держави і вирішення проблеми самовизначення національних меншин та етнічних груп в міжнародній практиці, показані і наведені схожі та відмінні риси з Нагорним Карабахом, який є територією Азербайджанської Республіки.

Самовизначення можна домогтися і без створення нових суверенних держав. У міжнародній практиці має місце й інший рівень самовизначення: національно-культурна автономія, яка сприяє збереженню представниками різних етнічних спільнот, зокрема нечисленними народами, національними та іншими меншинами самобутнього способу життя, своїх мов, культур, традицій і т.д. в рамках верховенства територіальної цілісності і суверенних прав держав, на територіях яких вони проживають.

Будь-який народ, будь-яка нація здатні вижити і розвиватися тільки в разі збереження специфічності своєї культури, культурної ідентичності. Азербайджан твердо дотримується принципів незалежного, правового і демо- 
кратичного суспільства. Азербайджанська Республіка завжди заявляла, що захист прав і свобод громадян розглядається як визначальний фактор існування демократичного суспільства.

Ключові слова: мультикультуралізм; Державна політика; право на самовизначення; національно-культурна автономія

$\mathrm{P}$ ешение проблемы социальной стабильности полиэтнического, культурного многообразия, с различными национально-этническими и религиозными особенностями имеет политическое и социальное значение. В настоящее время защита культурных прав, культурного разнообразия и своеобразия, развитие диалога между культурными обществами имеет актуальность. Современные полиэтнические и культурные общества не имеют возможности стабильно развиваться без правильной мультикультуральной политики государства. Так как мультикультурализм - это политика, направленная на сохранение и развитие культурных различий, диалог между культурами и цивилизациями, проявление толерантного отношения и уважения к представителям различных народов. Выше сказанное находит свое утверждение в статье 25 Конституции Азербайджанской Республики: «Государство гарантирует равенство прав и свобод каждого, независимо от расы, национальности, религии, языка, пола, происхождения и убеждений. Запрещается ограничивать в правилах и свободах человека и гражданина, исходя из расовой, национальной, религиозной, языковой принадлежности, пола, происхождения, убеждений, политической и социальной принадлежности» [7, статья 25].

Одним из доказательств вышесказанного является стабильное развитие Азербайджана, где обеспечивается мирное проживание представителей различных культур и религий. Испокон веков в государстве представители всех народов, наций, этнических групп жили в мире. В Азербайджане для развития традиций мультикультурализма имеются всевозможные политические и экономические условия.

Как отмечает В. А. Тишков, «национальная политика» в международной практике понимается как политика осуществления национальных интересов государства». Это же является - «государственная политика». «Внутренняя политика государства в отношении этнических общностей и межэтнических отношений обычно называется этнической политикой (ethnic policy) или политикой в отношении меньшинства (minority politics)» $[11,153]$.

Основным направлением национальной политики в Азербайджанском государстве является сохранение стабильной этнической ситуации и разрешение проблем этнического характера в полиэтническом государстве на основе принципов демократии и соблюдения прав и свобод эт- нических групп и учета интересов национальных меньшинств.

По А. Эйзенбер, национальные меньшинства могут потребовать некоторые права: территориальную автономию, гарантированное представительство в центральных институтах, претензию на землю и право на язык, защиту языка, религии, обычаев и земли $[1,10]$.

В политической практике в разных странах мира осуществляются различные формы мультикультурной политики.

Центральное место в вопросе о сохранении самобытности коренных народов занимает на практике правовое регулирование языковых отношений. Разные государства решают языковую проблему различными способами. Например, индийская модель мультикультурализма признает языковое многообразие населения, которое в 1950 г. нашло свое отражение в конституции Индии. Так как официальным языком в государстве является хинди, но существуют и английский, и многие другие языки, которые имеют официальный статус в штатах, где на них говорит большинство населения. В федеральном государстве Индии существует также религиозное многообразие: в нерабочие дни имеются пять индуистских, четыре мусульманских, два христианских, один буддистский, один джайнистский и один сикский праздники [9, 134]. Индия единственная страна, принявшая модель многоязычного, многонационального федерализма.

В Швейцарии, состоящей из равноправных кантонов, все граждане, традиционно принадлежащие к различным языковым сообществам, обладают равными правами в использовании родного языка. Равенство правового положения языковых групп или основных языков Швейцарии исходят из принципа равноправия кантонов [3, 104]. В первой статье Швейцарской конституции говорится: «Народ двадцати двух независимых кантонов Швейцарии объединен существующим альянсом... и вместе образует Швейцарскую Конфедерацию» [10, 49.].

В других государствах признается доминирование одного общенационального языка. Например, во Франции использование других языков, кроме французского, допускается в той мере, в какой не препятствует сохранению и развитию официального языка $[3,105]$.

В некоторых странах при предоставлении коренным нациям и народностям автономии соответствующего уровня учитывается их языковая 
особенность и территориальная принадлежность. Например, в Финляндии по этим показателям языковая и территориальная автономия предоставлена Аландским островам. На Аландских островах проживают 23 тыс. шведоговорящих и 1100 финноязычных граждан. Ввиду стратегического расположения островов, на протяжении многих веков Аландские острова были предметом геополитических игр нескольких крупных держав. Исторически острова входили в состав следующих государств: Швеция (1157-1809 годы); Россия (1809-1917 годы); Финляндия (с 1917 года) [6, 1].

В Акте об автономии Аландских островов (1922) говорится, что сохранение шведского языка, культуры, самобытности населения острова обеспечивается через создание автономии [4, 5051]. По закону о самоуправлении 1922 года, местный парламент - лагтинг - принимает законы о местном бюджете, внутренних делах, об образовании, здравоохранении, экономике, транспорте, коммунальном хозяйстве, полиции, почте, радио и телевидении на островах, определяет местное правительство. Для защиты интересов аландов его население выбирает одного депутата в парламент Финляндии. Губернатор островов назначается президентом Финляндии с одобрения лагтинга. Президент Финляндии имеет право вето на решения властей Аландов. Опыт Аландских островов может быть применен в Нагорном Карабахе [6, 2].

Созданная в 1867 году Квебекская Конфедерация получала права провинции с уточненными полномочиями между центром и провинцией. В Квебеке проживают 8 миллионов франкоязычных канадцев. Несмотря на усилия радикальных сепаратистов, большинство франкоязычных граждан выступают за территориальную целостность Канады. Сегодня права провинции достаточно высоки [6, 2]. Как отмечает У. Кимлика, права квебекцев защищены государством, так как они пропорционально представлены в национальных законодательных органах страны. В Квебеке, например, имеет силу собственная традиция гражданского права (наряду со Швейцарией, где сохраняется римская и немецкая правовые нормы, а в Шотландии - традиционная система права) [5].

В Южном Тироле Италии населения говорит на немецком и итальянском языках. Территориальные споры между Австрией, Италией и Германией велись многие десятилетия с XV века. В 1969 году был принят документ о статусе Южного Тироля, с большими полномочиями. Южный Тироль обладает правом законодательства и управления. Оборона и внешняя политика являются прерогативой Рима. Около 90\% собранных налогов остаются в провинции, из бюджета Италии в ЮТ переводятся дополнительные средства. Законодательные противоречия между законами Италии и
ЮТ разрешаются в Конституционном суде. В ЮТ многие государственные должности распределяются между двумя общинами в ротационном порядке [12, 3].

Портовый город Триест - столица итальянской автономной провинции Венеция-Джулия. Как в доисторические, так и в средние века, и во время Второй мировой война эта земля переходила из рук в руки. На нее претендовали Австрия, Италия и Германия. В 1945 году Триест был разделен между Югославией и союзными войсками победителей. Область демилитаризуется и считается нейтральной с обладанием гербом, флагом, губернатором, полицией, органами безопасности. Свободная экономическая зона Триест не может подписывать военные соглашения с другими странами, но вправе заключать договора в экономической, культурной, социальной и здравоохранительной областях. Губернатор области назначается в СБ ООН после согласования с Югославией и Италией. В Триесте два официальных языка - итальянский и словенский. По соглашению 1975 года, городская часть Триеста входит в состав Италии, а сельская отводится Югославии. В настоящее время эта часть принадлежит Словении. Трудно соотнести Триестскую модель с Карабахом, поскольку Триест на протяжении веков был независимым. Тем не менее, статус свободного города в составе Италии напоминает подготовленный ОБСЕ для Нагорного Карабаха промежуточный статус. А он таков, что центральная итальянская власть в дела города Триест не вмешивается, город действует в рамках полномочий, данных ему центром. Освободив себя от внешнеполитических, оборонных и других обязательств, власти Триеста сконцентрировались на развитии и благосостоянии жизни своих граждан $[12,4]$.

Ирландия (13,843 км, 1685267 чел.) как область имеет схожие и различные с Нагорным Карабахом особенности. Основное различие в том, что, в отличие от НК, Северная Ирландия, как это видно из названия, является исторической частью Ирландии. Но сегодняшняя реальность заключается в том, что Северная Ирландия входит в состав Великобритании.

Так же как в Нагорном Карабахе, часть жителей Северной Ирландии являются сторонниками территориальной целостности Великобритании, другая же группа под видом борьбы за независимость поднялась на вооруженный террор. В 1998 году подписывается устраивающее все стороны соглашение. Северная Ирландия остается в составе Великобритании, Ирландская Республика отказывается от территориальных притязаний к Великобритании, на этой основе области дается право широкого самоуправления [12, 4].

Последние годы и Шотландия (78772 км, 
5062011 чел.) в качестве области в составе Великобритании, претендуя на высший уровень самоопределения, выступает с требованием о пересмотре государственного устройства Англии. Во имя выхода Шотландии из состава соединенного Королевства шотландские националисты настойчиво требуют проведения референдума на территории данной автономной области. Ясно, что по международным правовым нормам независимость государства, изменение государственных границ рассматривается и решается на основе референдума, проведенного на всей территории страны с участием всех ее жителей. Шотландия в 1999 году, создавая свой региональный парламент, значительно расширила свои полномочия по руководству здравоохранением, образованием и сельским хозяйством [12, с.1].

Каталония является областью Испании, обладающей широкой автономией. Столица этой земли, на которой проживают 7 млн. населения (15\% от всего населения Испании) - город Барселона. Каталонцы сформировались из африканских иберийцев, переселившихся в Европу в 700 годах до нашей эры. Впервые Каталония получает статус в составе Испании в 1932 году. Каталония же во второй раз получает статус автономии в 1979 году. В парламенте Каталонии 135 депутатов, президент избирается на 4 года. В Каталонии два официальных языка - каталонский и испанский. Образование в государственных университетах на каталонском языке.

С точки зрения экономического развития, Каталония самая успешная область Испании, в ней производится 23\% ВВП от всей Испании. Совокупный доход Каталонии равен доходу Финляндии и Дании. В отличие от Каталонии, самозванная «НКР» нуждается в бюджете Азербайджанской Республики.

Новый статус, одобренный на референдуме 2006 года, уточняет разделение полномочий. Мадрид обязуется не вмешиваться в дела Каталонии, в сферу ее полномочий. Область получает широкие экономические права, половина собранных областных налогов остается в Каталонии. Порты, телекоммуникация, безопасность, юстиция и другие вопросы решаются на уровне Каталонии. Вопрос расширения статуса Каталония решает мирным путем, в диалоге с Испанией $[6,5]$.

Регламентация прав коренных малочисленных народов, связанных с их языковыми особенностями, не ограничивается международным универсальным и внутригосударственным уровнем. В частности, были приняты Декларация ООН 1992 г., в рамках Совета Европы в 1992 г. Европейская Хартия региональных языков и языков меньшинств, Рамочная конвенция Совета Европы, различные Рекомендации Верховного комиссара
ОБСЕ по делам национальных меньшинств (1996, 1998, 1999 гг.).

Согласно Хартии, под «региональными языками» и «языками меньшинств» понимаются языки, традиционно используемые группами численно меньшими, чем остальное население государства, и отличающиеся от официального языка данного государства [2, 1-2]. Что касается основных положений Хартии, укажем на некоторые из них. Во-первых, региональные языки и языки меньшинств признаются культурным богатством. Во-вторых, закрепляются конкретные меры, содействующие использованию указанных языков в общественной жизни. В-третьих, предусматривается предоставление государствами периодических отчетов Генеральному Секретарю Совета Европы.

Сегодня международное сообщество возвращается к идеям Версаля, пытается выработать политические принципы предоставления суверенитета национальным и этническим группам. В свое время президент Вудро Вильсон надеялся, что Версальские соглашения обеспечат каждой нации собственное государство. Эта надежда не везде была реализована в равной мере. Но ни Вильсон, ни другие архитекторы Версаля не утверждали, что каждое национальное меньшинство получит право на создание собственного государства дополнительно к уже существующему государству, где представители данной национальной группы составляют большинство. Так, например, обсуждая право еврейского народа на создание собственного государства в Эрец-Исраэль, участники Версальской конференции исключали возможность того, что евреи потребуют право на самоопределение в других странах, где они составляют значительную часть местного населения. Это исключение касается не только евреев, но и других наций, в том числе и армян, которые требуют отделения Нагорного Карабаха от Азербайджана.

Для того чтобы продемонстрировать абсурдность армянских претензий, можно привести убедительные примеры из сегодняшней национальной практики. Ни у кого не вызывает сомнения право литовцев на создание собственного независимого государства, или, иными словами, право Литвы на отделение от России, от Советского Союза. Литва воспользовалась этим правом. Но может ли претендовать на создание своего государства русское меньшинство в Литве? Ни один здравомыслящий человек не поддержит такое требование, поскольку русские уже располагают собственным государством в России. Точно так же чехи и словаки могут жить в одной стране или разделиться на два отдельных государства, но венгерское меньшинство в Словакии не может требовать права на самоопределение в виде сецессии, 
поскольку у венгров уже имеется собственное государство - Венгрия.

Во многих странах мира имеются значительные национальные и этнические меньшинства. Следует ли признать за каждым национальным меньшинством в этих странах право на самоопределение до уровня независимого государства? От такого кошмара не застрахованы даже Соединенные Штаты Америки. Не исключено, что в течение одного-двух десятилетий в некоторых штатах на юго-западе США образуется испаноязычное большинство в виду постоянной иммиграции из Мексики. Среди испаноязычных граждан могут появиться лидеры, которые в собственных интересах потребуют не равноправия перед законом, а права на создание собственного государства в тех районах, где испаноязычные жители составляют большинство. Это требование будет обосновано еще тем, что соответствующие районы принадлежали раньше Мексике и были завоеваны Соединенными Штатами Америки в 1848 г.

По иронии судьбы неизбежным следствием «требования второго государства» явится пренебрежение к правам национальных меньшинств во всем мире. Если каждое меньшинство (которое не имеет юридического и морального права на «отделение») будет угрозой целостности и жизнеспособности того государства, в котором оно проживает, то представители доминантной нации будут изыскивать пути для подавления и ликвидации сепаратизма национальных меньшинств в пределах своих границ.

Дарование всем без разбора права на "самоопределение" - это политическая бомба, способная взорвать гражданский мир во многих странах и привести к конфликтам между государствами, на территории которых имеются значительные национальные меньшинства.

Самоопределения народов и наций можно до- биться и без возникновения новых суверенных государств. Существует институт автономии, учитывающий культурное многообразие. Автономия не означает сецессию, которая ведет к независимости, а наоборот представляет национальным меньшинствам возможность сохранения этнического своеобразия, решения вопросов развития религии, культуры, языка, образования, экономики. Как отмечает специалист по данному вопросу Руфь Лапидот, автономия имеет три типа: политическая территориальная, административная и персональная (или культурная). Политическая территориальная автономия представляет собой совокупность мер, направленных на обеспечение определенной степени самоидентификации группы, отличающейся от большинства населения государства, но представляющей, в свою очередь, большинство в определенном регионе. Автономия предполагает перераспределение полномочий между центральной властью и автономным территориальным образованием [8, 26-33].

Центральное правительство не контролирует полностью все действия органов власти автономии, но может воспользоваться правом вето в случае превышения последними своих полномочий.

Административная автономия ограничивается вопросами управления и приближается таким образом к децентрализации. Персональная (или культурная) автономия предоставляет право сохранять и развивать религиозные, языковые и культурные практики соответствующей группы с помощью создаваемых ею самой общественных институтов. Государство признает за этими институтами право на принятие обязательных к исполнению решений и на взимание налогов [8, 26-33].

Таким образом, право национальных меньшинств не создавать новое государство, а пользоваться автономией в рамках мультинационального государства.

\section{БІБІЛІОГРАФІЧНІ ПОСИЛАННЯ}

1. Эйзенберг А. Равенство, доверие и мультикультурализм / А. Эйзенберг // Доверие к социальному разнообразию. - 2002 г. - С. 1-30

2. Европейская хартия региональных языков меньшинств 1992 года. - Страсбург, 1992 г.

3. Крылова И. С. Национальная самобытность народа и правовое регулирование / И. С. Крылова // Государство, право и межнациональные отношения в странах западной демократии. - М., 1993. - С. 104-105.

4. Крылова Н. С. Автономия как способ урегулирования межэтнических отношений / Н. С. Крылова, Т. А. Васильева // Государство, право и межнациональные отношения в странах западной демократии. М., 1993.

5. Кимлика У. Политика, учитывающая культурные особенности / У Кимлика // Докладчик по вопросам развития человеческого потенциала, разработанный Организацией Объединенных Наций. - 2004 г. - № 5.

6. Кямал Али. 10 статусов для Нагорного Карабаха / Али Камял // Южный Кавказ, Центральная Азия и СНГ в мировой печати «Южный Кавказ», 26 января 2011 года. - Режим доступа: http://azeritoday.com/archives/23762.

7. Конституция Азербайджанской Республики (1995). - Баку, 1996. - 50 с.

8. Рут Лапидот. «Характеристики автономии». in Centre europeen des questions de minorities (Есті) / Рут Лапидот // Autonomies insularies: versunepolitique de la difference pour la Corse. - Албания, 1999. - С. 26-33.

9. Ронан Ле Коадик. Мультикультурализм. - Режим доступа: ethno-photo.livejournal.com/15997.html 
10. Стоянович Н. Швейцарское национальное государство и его патриотизм - критика отчета Уилла Кимлика, посвященного многоязычным государствам / Н. Стоянович // Полис. - 2003 г. - Т. 11. - С. 49.

11. Тишков В. Очерки теории и политики этничности в России / В. Тишков. - М.: Институт этнологии и антропологии РАН, 1997. - 529 с.

12. Троицкая О. Великобритания согласилась с правом Шотландии на самоопределение / О. Троицкая. - Режим доступа: http://www/ng.ru/courier/2012-03-05/10 scotland/html.

\section{REFERENCES}

1. Eisenberg, A.( 2002). Ravenstvo, doverie i mul'tikul'turalizm [Equality, trust and multiculturalism]. Trust for social diversity, (pp. 1-30) [in Russian].

2. Europen Charter for Regional of Minority languages. (1992). Strasburg [in Russian].

3. Krylova, I.S. (1993). Nacional'naja samobytnost' naroda i pravovoe regulirovanie [National identity of a people and legal regulation]. State, law and interethnic relations in the countries of Western democracy, (pp.104-105). Moscow [in Russian].

4. Krylova, N.S., \& Vasilyeva, T.A. (1993). Avtonomija kak sposob uregulirovanija mezhjetnicheskih otnoshenij [Autonomy as a way of settling interethnic relations]. State, law and interethnic relations in the countries of Western democracy. Moscow [in Russian].

5. Kymlicka, W. (2004). Politika, uchityvajushhaja kul'turnye osobennosti [Cultural responsive policies]. United Nations development programmer human development report office, 5 [in Russian].

6. Kamal, Ali. (2011). 10 statusov dlja Nagornogo Karabaha [10 statuses for Upper Garabagh]. South Caucasus, Central Asia and the CIS in the world press South Caucasus. Retrieved from: http://azeritoday.com/archives/23762 [in Russian]. 7. Konstitucija Azerbajdzhanskoj Respubliki [Constitution of the Republic of Azerbaijan]. (1995). Baku.

8. Lapidoth, Ruth. (1999). Les Caracteristiques de L'autonomie, in Centre europeen des questions de minorities (Ecmi). Autonomies insularies: versunepolitique de la difference pour la Corse, (pp. 26-33). Albania.

9. Ronan Le Coadic. (2003). Multiculturalysm. Retrieved from: ethno-photo.livejournal.com/15997.html [in Russian].

10. Stojanovic, N. (2003). Shvejcarskoe nacional'noe gosudarstvo i ego patriotizm - kritika otcheta Uilla Kimlika, posvjashhennogo mnogojazychnym gosudarstvam [Swiss nation-state and its patriotism a critique of Will Kymlick's account of multination states]. Polis, 11, 49 [in Russian].

11. Tishkov, V. (1997). Ocherki teorii $i$ politiki jetnichnosti $v$ Rossii [Essays on the theory and policy of ethnicity in Russia]. Moscow: Institute of Ethnology and Anthropology, Russian Academy of Sciences [in Russian].

12. Troitskaya, O. (2012). Velikobritanija soglasilas's pravom Shotlandii na samoopredelenie [UK agreed with the right of Scotland to self-determination]. Retrieved from: http://www/ng.ru/courier/2012-03-05/10 scotland/html [in Russian].

\section{Ирада Нуриева Тофик Гызы}

Доктор политических наук, профессор

Азербайджанский Государственный Университет Нефти и Промышленности

А3-1010, г. Баку, пр. Азадлыг, 20

\section{Irada Nuriyeva Tofiq}

Doctor of Political science, professor

Azerbaijan State University of Oil and Industry

20, Azadlıq Ave., AZ-1010, Bacu, Azerbaijan

Email: iradanuri@gmail.com

Цитування: Ірада Нурієва Тофік Гизи. Мультикультуралізм і проблеми самовизначення етнокультурних меншин / Ірада Нурієва Тофік Гизи // Науково-теоретичний альманах «Грані». - 2018. - Т. 21. - № 4. C. 34-39.

Citation: Irada Nuriyeva Tofiq (2018). Multykulturalizm i problemy samovyznachennia etnokulturnykh menshyn [Multiculturalism and the problems of self-determination of ethnocultural minorities]. Scientific and theoretical almanac «Grani», 21(4), 34-39. 